\title{
The relationship between neurocysticercosis and the development of mesial temporal lobe sclerosis
}

\section{A relação entre neurocisticercose e o desenvolvimento de esclerose temporal mesial}

To the editor:

The work by Oliveira, et al. published in the journal last July addressed once again the interesting question regarding the relationship of chronic calcifications suggestive of neurocysticercosis (NC) and the development of mesial temporal lobe epilepsy with hippocampal sclerosis (MTE-HS) ${ }^{1}$. The publication concluded that there is a higher incidence of brain calcifications suggestive of NC in patients with MTS-HS, when compared to a control of other epilepsy syndrome populations. This conclusion corroborates similar findings published by different groups previously ${ }^{2}$. Since neurocysticercosis is largely implicated as the cause of epilepsy in the developing world, including Brazil, our group considered this work very important as the catalyst for future discussions and research in this subject. As pointed out in the discussion session, many questions are still to be answered: What is the potential mechanism involved in the development of MTS-HS in these patients? More importantly, who is at increased risk of developing MTS-HS from NC infections? The predominant incidence of calcifications in the ipsilateral temporal lobe points towards a possible local mechanism, as mentioned in the article. In addition, repeated clinical and sub-clinical seizures, triggered during the acute NC phase appear as potential sources of initial precipitating injuries. Recent abstract presented by our group from Fortaleza-Brazil at the 2013 American Academy of Neurology meeting pointed out an increased incidence of white matter disease and lacunar strokes in patients with calcified lesions suggestive of NC, which also raises the hypothesis that local inflammatory reactions may be associated to these findings ${ }^{3}$. It also revealed a prevalence of calcifications suggestive of $\mathrm{NC}$ of $2.7 \%$ in a general population who underwent brain $\mathrm{CT}$ scan for several different reasons, not only convulsions. Nevertheless, as stated by Oliveira et al., there is still a possibility that the calcifications identified by CT brain are not from NC. The current criteria developed by Del Brutto et al. ${ }^{4}$ addresses potential active forms of NC, but we lack a more precise way of identifying intra-cerebral calcifications as "incomplete" or "halted" forms of infection by Taenia solium. As suggested, adding epidemiological criteria, such as contact with pigs or living in rural areas, might help. Serological and pathological studies would add to this quest. The answers for these questions will help identifying why some patients do not appear to develop the active form of NC, while others suffer from acute and late effects of this disease.

\footnotetext{
Vitor Hugo Pacheco ${ }^{1}$, Francisco de Assis Aquino Gondim², Adriana de Menezes Gomes ${ }^{3}$, Hayato Augusto Hossoé Corrêa ${ }^{2}$, Marlon Sousa Silva ${ }^{3}$, Gabriela de Andrade Meireles Bezerra ${ }^{3}$, Maria Rocha Costa ${ }^{3}$ about an old disease. Lancet Neurol. 2005;4(10):653-61. http://dx.
}

3. Gondim FA, Sales PM, Silva M, Gomes A, Lima JW, Bezerra G et al. Increased prevalence of lacunar strokes and severe white matter disease in patients with neurocysticercosis. Neurol. 2013;80(meeting abstracts 1).

4. Garcia $\mathrm{HH}$, Del Brutto $\mathrm{OH}$. Neurocysticercosis: updted concepts doi.org/10.1016/S1474-4422(05)70194-0

\section{References}

1. Oliveira MCB, Martin MGM, Tsunemi MH, Vieira G, Castro LHM. Small calcified lesions suggestive of neurocysticercosis are associated with mesial temporal sclerosis. Arq Neuropsiquiatr. 2014;72(7):510-6. http://dx.doi.org/10.1590/0004-282X20140080

2. Velasco TR, Zanello PA, Dalmagro CL, Araújo Junior D, Santos AC, Bianchin MM et al. Calcified cysticercotic lesions and intractable epilepsy: a cross sectional study of 512 patients. J Neurol Neurosurg Psychiatry. 2006;77(4):484-8. http://dx.doi.org/10.1136/jnnp.2005.078675

\footnotetext{
${ }^{1}$ Baylor College of Medicine, Department of Neurology, Michael E. DeBakey VA Medical Center, Houston TX, USA;

${ }^{2}$ Universidade Federal do Ceará, Departamento de Medicina Clínica, Fortaleza CE, Brazil;

${ }^{3}$ Faculdade de Medicina Unichristus, Fortaleza CE, Brazil.

Correspondence: Vitor Hugo Pacheco; Rua Dr. Marlio Fernandes, 81 / ap. 404-C; 60810-025 Fortaleza CE, Brasil; E-mail: pacheconeuro@gmail.com

Conflict of interest: There is no conflict of interest to declare.
}

Received 01 October 2014; Received in final form 08 October 2014; Accepted 28 October 2014. 